\title{
(2) OPEN ACCESS \\ Successful rescue from kidney failure with delayed catheter-directed intervention after catastrophic bilateral kidney paradoxical thromboembolism
}

\author{
Jing Loong Lim, ${ }^{1}$ Kenneth K Lau $\bullet^{2,3}$ Andy K H Lim $\circledast^{3,4}$
}

\begin{abstract}
${ }^{1}$ General Medicine, Monash Health, Clayton, Victoria, Australia

${ }^{2}$ Monash Imaging, Monash Health, Clayton, Victoria, Australia

${ }^{3}$ Medicine, Monash University School of Clinical Sciences at Monash Health, Clayton, Victoria, Australia

${ }^{4}$ General Medicine and Nephrology, Monash Health, Clayton, Victoria, Australia
\end{abstract}

\section{Correspondence to} Associate Professor Andy K H Lim; andy.lim@monash.edu

Accepted 7 January 2022

\section{Check for updates}

(c) BMJ Publishing Group Limited 2022. Re-use permitted under CC BY-NC. No commercial re-use. See rights and permissions. Published by BMJ.

To cite: Lim JL, Lau KK, Lim AKH. BMJ Case Rep 2022;15:e246885. doi:10.1136/bcr-2021246885

\section{SUMMARY}

A 62-year-old man presented with acute abdominal and flank pain, oligoanuria and severe acute kidney injury. Unenhanced CT imaging did not detect urolithiasis or hydronephrosis. There was an early blood pressure surge followed by an intense inflammatory response, with a rise in peripheral blood leucocytes and $\mathrm{C}$ reactive protein. His urinalysis was bland but the serum lactate dehydrogenase was markedly elevated. CT angiograms demonstrated multiple pulmonary emboli and bilateral renal artery thromboembolism, with occlusion of the left main renal artery. Despite an 88-hour delay from pain onset, catheter-directed thrombolysis and thromboaspiration of both renal arteries were successfully performed, allowing the patient to recover enough kidney function to cease haemodialysis. A patent foramen ovale with right-to-left shunting was discovered, and paradoxical embolism was suspected as the cause of renal infarction. The benefit of catheter-directed reperfusion after prolonged bilateral renal ischaemia is not easily predicted by the severity or duration of acute kidney injury alone.

\section{BACKGROUND}

Renal infarction is uncommon, but acute bilateral infarction can result in immediate kidney failure and permanent dialysis requirement. Any chance at rescue therapy should be immediately assessed and offered if possible. Endovascular catheter-directed treatment is preferred to systemic thrombolysis, but there is uncertainty as to the acceptable treatment time window. This case report highlights the clues at presentation which indicates renal infarction so clinicians may better recognise this syndrome. It also demonstrated that some patients still benefit from delayed intervention. Paradoxical embolism is also a very rare cause of renal infarction which was worth considering if a primary cardiac source cannot be found.

\section{CASE PRESENTATION}

A 62-year-old man presented with acute onset severe abdominal pain which woke him from sleep. The pain was constant, predominantly in the left flank and radiated to the groin, and was associated with nausea, vomiting and diaphoresis. He initially believed it was similar to the renal colic he experienced 5 years ago, where a $4 \mathrm{~mm}$ vesicoureteric calculus was found. His medical history included type 2 diabetes and overweight (body mass index $27.3 \mathrm{~kg} / \mathrm{m}^{2}$ ), and chronic kidney disease with an estimated glomerular filtration rate of $78 \mathrm{~mL} /$ $\min / 1.73 \mathrm{~m}^{2}$. He had recently undergone elective sinus and nasal surgery (open septorhinoplasty, right functional endoscopic sinus surgery and bilateral turbinoplasty) 3 days prior to presentation and was discharged on a 5-day course of oral cephalexin and celecoxib. His regular medication included metformin, and he was a non-smoker who was independent with his activities of daily living.

He presented to hospital 3 hours after the onset of pain with a regular heart rate of 66 beats per minute and a blood pressure of $130 / 80 \mathrm{~mm} \mathrm{Hg}$. The admission ECG confirmed a sinus rhythm. Abdominal and rectal examination did not define any focal areas of tenderness or guarding. A non-contrast CT scan of his kidney, ureter and bladder did not show ureteric calculi or hydronephrosis. Several surgical consults were undertaken but the differential diagnosis remained broad, and he was initially managed with intravenous fluids and opioid analgesia. However, his abdominal pain evolved to involve both flanks and he was oligoanuric. The urinalysis was bland (leucocytes, $7 \times 10^{6} / \mathrm{L}$; erythrocytes, $4 \times 10^{6} / \mathrm{L}$ ), but the urine protein-to-creatinine ratio was significantly elevated at $0.99 \mathrm{~g} / \mathrm{mmol}$ (normal, $<0.03 \mathrm{~g} / \mathrm{mmol}$ ).

Within hours of presentation, there was a surge in the systolic blood pressure with spikes up to $175 \mathrm{~mm} \mathrm{Hg}$ despite adequate analgesia. His heart rate remained normal in the first 24 hours, but steadily increased thereafter, with sinus tachycardia on telemetry. Blood leucocyte count was elevated at presentation, and after a 24-hour delay, the $\mathrm{C}$ reactive protein also increased dramatically. An evolving acute kidney injury (AKI) was evident. These observations are summarised in figure 1 . Renal doppler ultrasound noted a loss of perfusion bilaterally, and the serum lactate dehydrogenase was significantly elevated at $2601 \mathrm{U} / \mathrm{L}$ (normal, $<250 \mathrm{U} / \mathrm{L}$ ). A CT thoracic and abdominal angiogram was eventually performed 81 hours after the onset of pain. A brief episode of atrial fibrillation was detected immediately after the procedure, which spontaneously reverted after 4 hours.

\section{INVESTIGATIONS}

The CT angiogram excluded aortic dissection and demonstrated extensive non-occlusive thromboemboli in the right renal artery (figure $2 \mathrm{~A}$ ) and left renal artery occlusion (figure $2 \mathrm{~B}$ ). In addition, acute pulmonary emboli were found in the right lower lobe pulmonary arteries involving the 

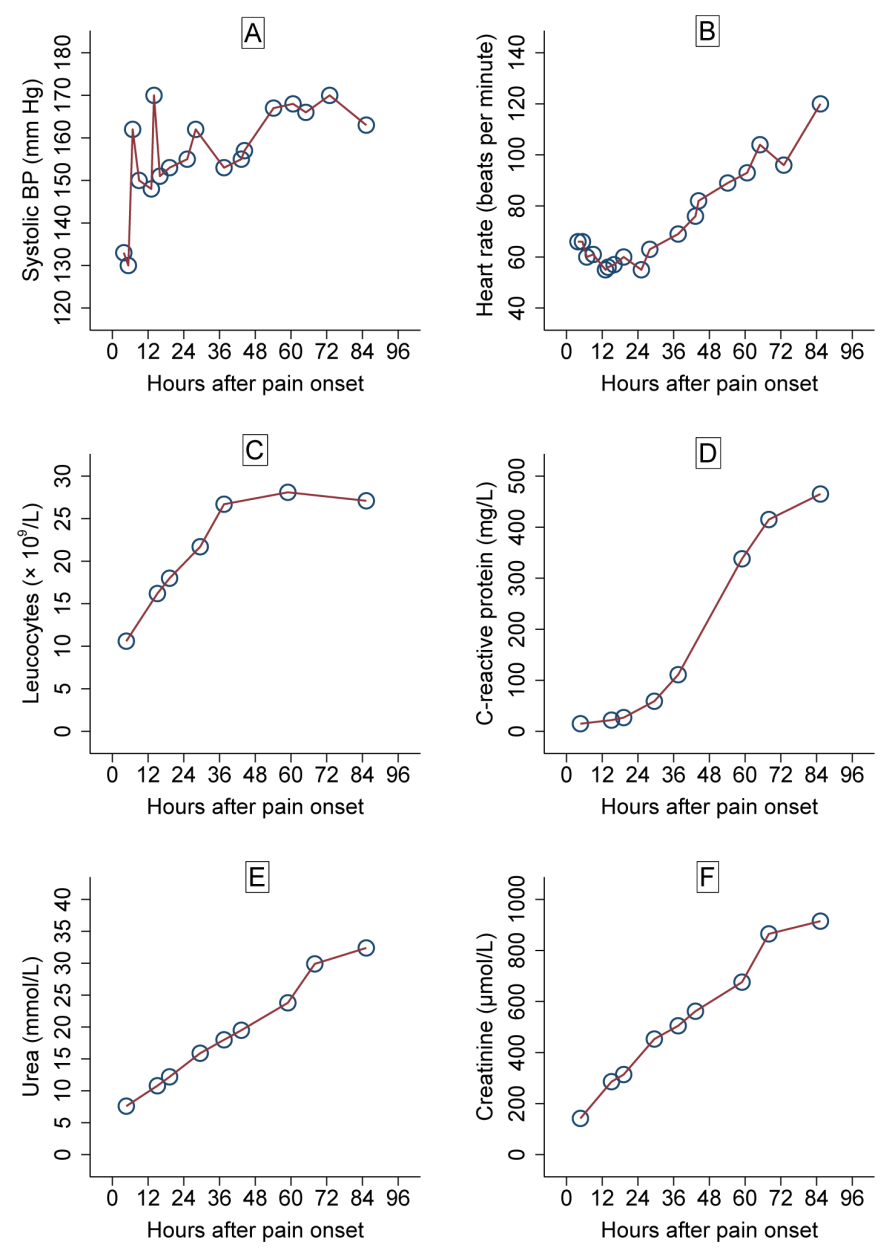

Figure 1 Graphs of haemodynamic and blood parameters prior to initiation of dialysis. There was an early surge in systolic blood pressure occurring a few hours after pain onset $(A)$, with heart rate rising steadily after 36 hours (B), both indicative of neurohormonal activation. Renal infarction was associated with marked inflammation, with an early rise in blood leucocytes which peaked around 48 hours (C), with the $C$ reactive protein increasing dramatically after a 24-36-hour delay (D). Acute kidney injury was evident by the rapidly rising serum urea (E) and creatinine levels (F), and haemodialysis was commenced shortly after the last charted result.

medial, posterior and lateral basal segment pulmonary arteries (figure 2C). There were no filling defects within the left heart to suggest a cardiac source of emboli, and the visceral branches of the abdominal aorta were widely patent.

\section{DIFFERENTIAL DIAGNOSIS}

An echocardiogram detected a patent foramen ovale (PFO) with significant right-to-left shunting of saline bubble contrast, but no intracardiac thrombus. In retrospect, the PFO was noted on a CT coronary angiogram 4 years prior (figure 3), but the patient had been previously asymptomatic. Paradoxical embolism was deemed the most likely cause of renal infarction, given the recent hospitalisation and surgery as a provoking factor for venous thromboembolism, and the concurrent pulmonary embolism. Other causes were considered but investigations for thrombophilia and autoimmune disease were unremarkable. No monoclonal proteins were detected in serum or urine. Malignancy was not detected on imaging to suggest a paraneoplastic syndrome.
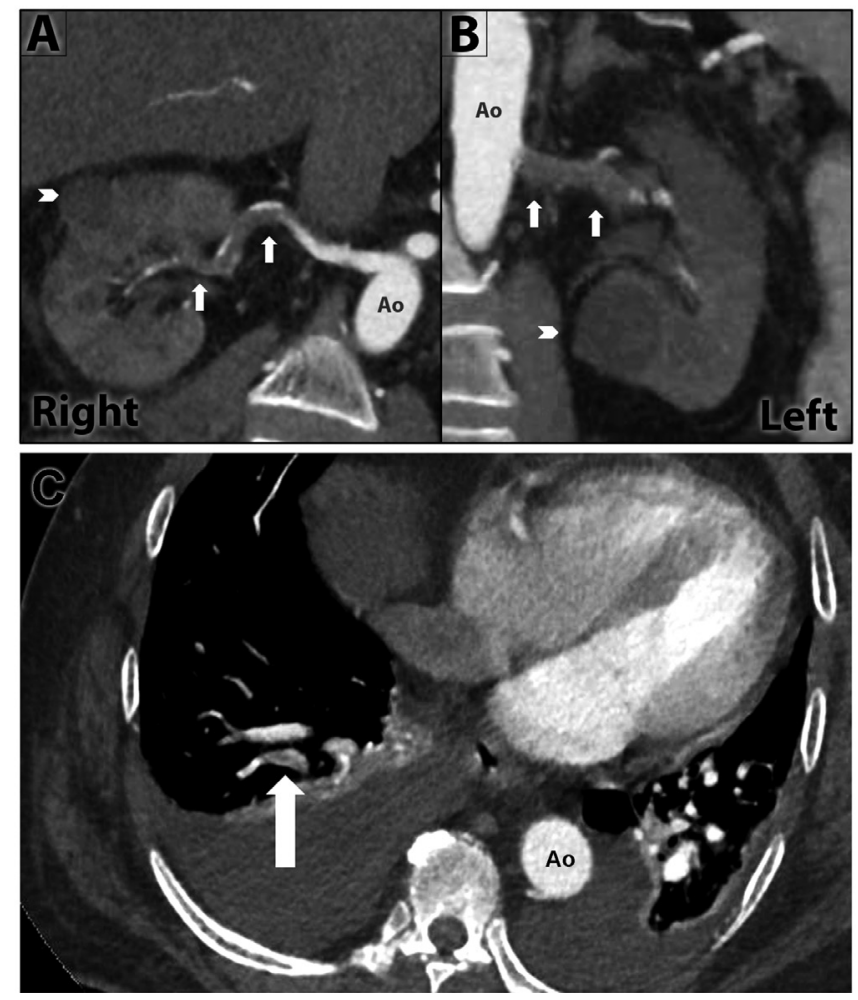

Figure 2 Coronal sections of contrast-enhanced CT angiogram demonstrated extensive filling defects (white arrows) within the right renal artery (A) and left renal artery (B), consistent with extensive thromboembolism. Thrombus was occluding the ostium of the left main renal artery (B). The white arrowheads represent simple cysts. (C) CT pulmonary angiogram demonstrated filling defects in segmental and subsegmental branches of the right lower lobe pulmonary arteries in keeping with pulmonary embolism (white arrow), in addition to moderate bilateral pleural effusions. Ao, Aorta.

\section{TREATMENT}

The patient commenced anticoagulation with intravenous heparin and proceeded to an emergency catheter-directed thrombolysis (urokinase) with mechanical and suction thrombectomy of both

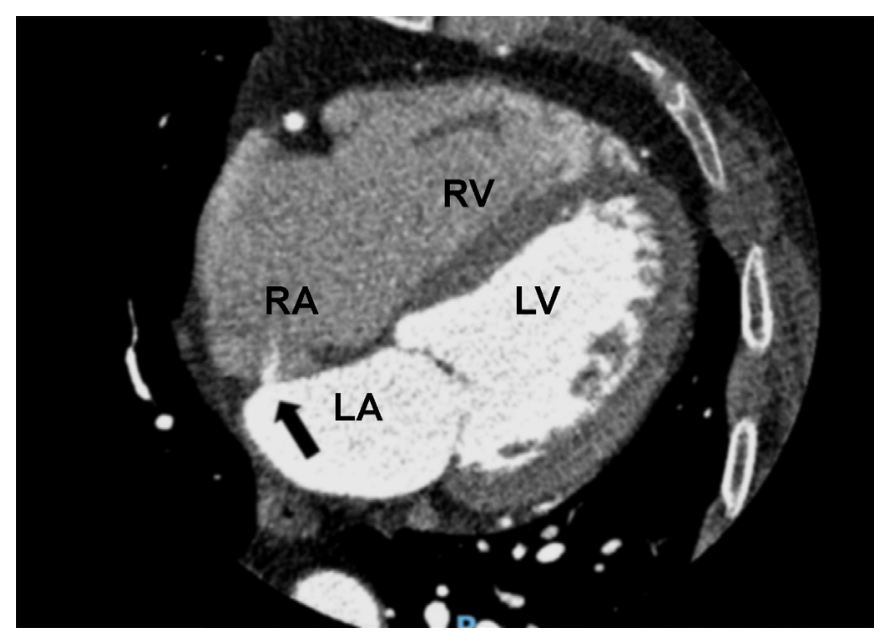

Figure 3 A previous ECG-gated CT coronary angiogram demonstrated a $2 \mathrm{~mm}$ patent foramen ovale (black arrow), with iodinated contrast leak through the defect. LA, left atrium; LV, left ventricle; RA, right atrium; RV. right ventricle. 


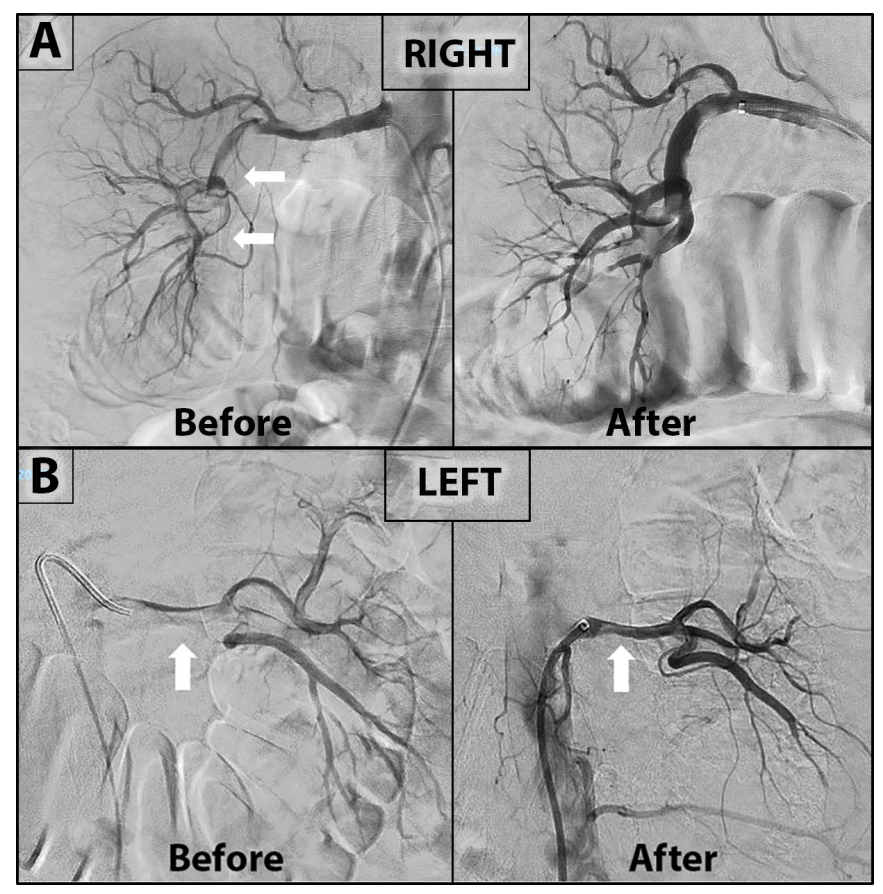

Figure 4 Selective catheter angiogram of renal arteries. (A) The right renal artery angiogram demonstrated moderate-large embolic burden before intervention, more prominent in the distal main artery and its branches (white arrows). Repeat angiogram after mechanical (suction) and chemical (urokinase) thrombectomy revealed significant improvement of the right renal circulation. (B) The left renal artery angiogram before intervention confirmed extensive thromboembolism which was most severe in the left main renal artery (white arrow) and its ostium. Repeat angiogram after thrombectomy showed marked improvement of the left renal circulation with a small amount of residual emboli (white arrow).

renal arteries. Satisfactory angiographic restoration of perfusion (figure 4) and retrieval of multiple clots (figure 5) was achieved approximately 88 hours after pain onset. However, due to worsening metabolic acidosis ( $\mathrm{pH} 7.24$, bicarbonate $17 \mathrm{mmol} / \mathrm{L}$ ) and persistent anuria, he was commenced on haemodialysis 94 hours after symptom onset. A timeline of the major investigations and intervention is shown in figure 6.

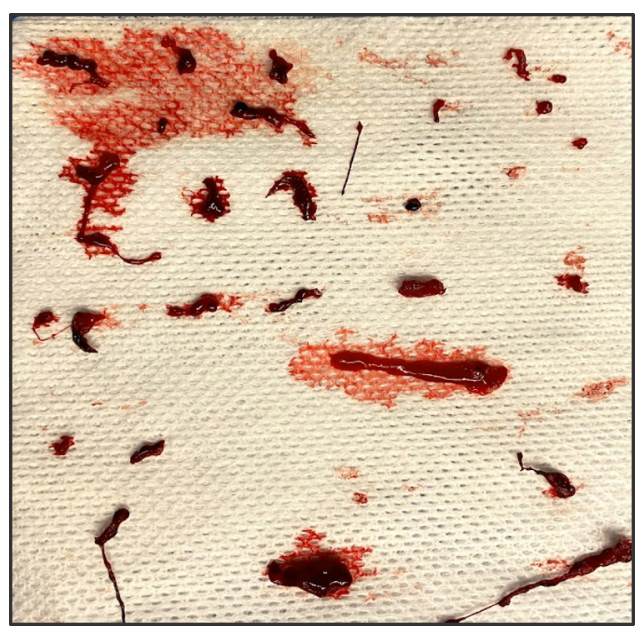

Figure 5 Multiple fragments of embolic material were successfully retrieved from the renal arteries during suction thrombectomy.

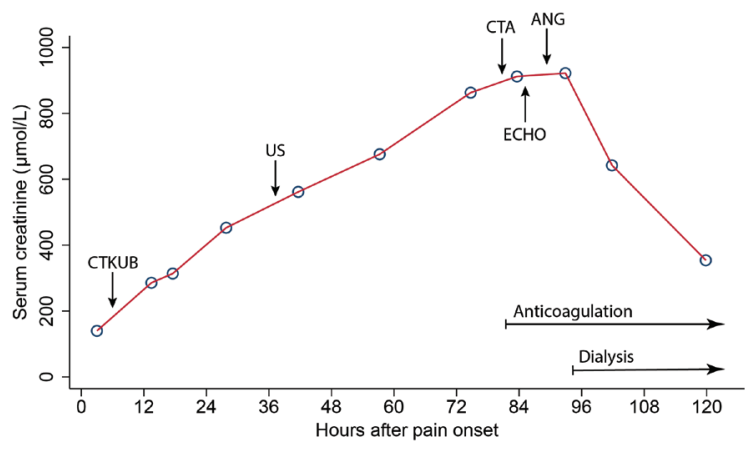

Figure 6 Timeline of investigations and interventions relative to the onset of symptoms, superimposed on a graph of the serum creatinine showing acute kidney injury. ANG, angiographic catheter-directed suction thrombectomy and thrombolysis; CTA, CT angiogram of pulmonary and renal arteries; CTKUB, non-contrast CT kidney ureter bladder; ECHO, echocardiogram; US, renal ultrasound.

\section{OUTCOME AND FOLLOW-UP}

Postreperfusion, there was a steady improvement in his daily urine output: day $1(155 \mathrm{~mL})$, day $2(435 \mathrm{~mL})$, day $3(660 \mathrm{~mL})$, day $4(2050 \mathrm{~mL})$. After a period of heparinisation, the patient transitioned to warfarin anticoagulation. He was able to cease haemodialysis 30 days after initiation, having recorded a stable predialysis creatinine around $320 \mu \mathrm{mol} / \mathrm{L}$. After another 4 months follow-up, he maintained a stable creatinine of $280 \mu \mathrm{mol} / \mathrm{L}$ with an estimated glomerular filtration rate of $20 \mathrm{~mL} / \mathrm{min} / 1.73 \mathrm{~m}^{2}$ and a urine protein-to-creatine ratio of $0.07 \mathrm{~g} / \mathrm{mmol}$. Repeat renal ultrasound noted some areas of cortical atrophy consistent with patchy cortical necrosis but arterial doppler interrogation showed normal resistive indices and intrarenal waveforms bilaterally, without evidence of renal artery stenosis or residual thromboembolism. He maintains sinus rhythm, and PFO closure by a percutaneous transcatheter technique is under consideration by his cardiologist and haematologist.

\section{DISCUSSION}

Renal infarction is a rare diagnosis which can present as an undifferentiated acute abdomen or mimic renal colic. Even with surgical consultation, the diagnosis was delayed in our patient. In a case series of 94 patients, the average time to diagnose renal infarction was 5 days. ${ }^{1}$ Furthermore, extrarenal infarction only occurs in $10 \%-16 \%$ of cases. ${ }^{12}$ The preferred initial diagnostic test for flank pain is a non-contrast CT as it is the gold standard for the diagnosis of renal (ureteric) calculi, which is much more common than renal infarction. In our patient, his history of ureteric calculus and initial presentation with unilateral flank pain prompted a consideration of recurrent calculus. However, as shown in this case, a non-contrast CT aimed at detecting urolithiasis or hydronephrosis does not detect perfusion abnormalities, and renal infarction can be missed due to a false reassurance of the apparently normal non-contrast CT. Ultrasound as the initial scan may have been appropriate to exclude a postrenal cause of AKI but it does not localise the level of obstruction, and doppler interrogation is not routinely performed. A contrast-enhanced CT is the imaging method of choice if renal infarction is clinically suspected.

Clinicians need a high index of suspicion to diagnose renal artery occlusion so that reperfusion therapy can be attempted 
in a timely manner. The clinical features which suggested renal infarction included abdominal/flank pain, reduced urine output and markedly elevated lactate dehydrogenase. Another clue is the acute surge in blood pressure which is most likely driven by activation of the renin-angiotensin system from renal ischaemia. In unilateral renal artery occlusion, increased reninangiotensin driven hypertension results in pressure natriuresis in the contralateral kidney, which partially attenuates the progression of hypertension despite high levels of renin. With bilateral renal artery occlusion, this pressure natriuresis is lost, leading to rapid sodium and volume retention, and progressive hypertension. The hypertension may be difficult to control without fluid offloading, and in the case of bilateral renal infarction with anuria, acute dialysis and ultrafiltration can be effective in controlling the hypertension. The delayed rise in heart rate may be due to the sympatho-adrenergic activation, oxidative stress, and a proinflammatory state corresponding with the significant elevation in blood leucocyte count and $\mathrm{C}$ reactive protein seen in many cases of renal infarction. ${ }^{1}$ In our case, the finding of AKI was an initial deterrent for contrast imaging after the impaired perfusion was initially identified on doppler ultrasound. However, the CT angiogram was the most sensitive and specific investigation for diagnosis of renal artery occlusion.

The most common cause of renal infarction is cardiac thromboembolism, mostly as a consequence of atrial fibrillation. Other causes include a de novo thrombosis due to thrombophilia or renal artery trauma, but around $30 \%$ are idiopathic and $16 \%$ are bilateral. ${ }^{1-3}$ However, we suspect our patient had paradoxical embolism because of the concurrent pulmonary embolism and presence of a PFO, even though lower limb deep vein thrombosis was not found. His recent surgery was considered the provoking factor for the thromboembolic event. It was also possible that a left atrial appendage thrombus could have been missed despite excellent views on transthoracic echocardiography. However, a left atrium source of thrombus did not explain the pulmonary embolism. The patient was in sinus rhythm on admission and throughout most of the monitoring period, except for a brief episode of atrial fibrillation lasting 4 hours occurring immediately after his CT angiogram (81 hours after pain onset), which we believe was triggered by acute illness (renal failure, pulmonary embolism, hypoxia, pain, iodinated contrast). In all ECG and telemetry recordings before and after this brief episode, he remained in sinus rhythm (up to 4 months follow-up).

Case reports of bilateral renal infarction from paradoxical emboli are rare. ${ }^{4-7}$ Carey et al reported a patient with bilateral renal artery occlusion in the setting of a deep vein thrombosis and PFO who remained dialysis dependent. ${ }^{4}$ In the case by Herbaut et al, the infarcted kidney was not salvageable after a significant delay in diagnosis and treatment. ${ }^{6}$ Our patient was fortunate to have salvaged enough kidney to cease dialysis. Only one other case by Goueffic et al reported a similar situation, where a patient with bilateral renal infarct following paradoxical embolism recovered enough renal function to cease dialysis after successful endovascular treatment. ${ }^{7}$ In the longer term, it is unclear if closure of the PFO is recommended as studies have mostly been for secondary stroke prevention. In a metaanalysis of randomised trials by Shah et al in 2018, PFO closure compared with medical therapy alone reduced the rate of recurrent stroke from $5.1 \%$ to $1.8 \%{ }^{8}$ In an observational study of patients with paradoxical embolism and PFO, the average annual recurrence of transient ischaemic attacks and peripheral embolism despite PFO closure was $2.5 \%$ and $0.9 \%$, respectively. ${ }^{9}$ While there are many reported case studies of PFO closure after non-cerebral paradoxical embolism in the literature, it is difficult to conclusively demonstrate a benefit in the absence of randomised trials. However, given the catastrophic embolism in our patient and the indirect evidence for preventing peripheral embolism, percutaneous transcatheter PFO closure is under consideration for our patient.

Bilateral renal artery occlusion can lead to permanent kidney failure. Open surgical thrombo-embolectomy has largely been replaced by percutaneous endovascular treatment as it is associated with lower morbidity, mortality and recovery time. To our knowledge, surgery has not been first-line treatment for renal artery thromboembolism since the 1980s, and it is not superior to endovascular treatment for the salvage of renal function. ${ }^{10}$ The window for reperfusion with intra-arterial thrombolysis and thromboaspiration has traditionally been considered to be small. Previous case reports of successful catheter-directed thromboaspiration after an acute renal artery occlusion had usually performed them within $12-24$ hours from the onset of pain. ${ }^{711-14}$ However, these procedures are not commonly performed due to the uncommon occurrence of renal artery occlusion, so there is insufficient data to adequately define the treatment time window. Our case demonstrated a benefit of endovascular reperfusion even after a significant delay of 88 hours from the onset of pain. The success rate of endovascular treatment is unknown due to selection bias, publication bias and heterogeneity between cases. In a case series, 33 of 94 patients with acute renal infarction underwent interventional angiography following initial CT diagnosis, but only five patients were deemed suitable for curative treatment. Of these, four patients demonstrated improved renal function while one patient with bilateral involvement failed treatment and remained dialysis dependent. ${ }^{1}$ However,

\section{Patient's perspective}

$\mathrm{Hi}$, I'm [anonymised], the Drs at [anonymised] have requested me to write a few lines about what happened to me and how I lost my kidney function pretty much overnight.

After much procrastination I decided to have a septoplasty and rhinoplasty operation. The operation was a success but 2 days later, I started having severe abdominal cramps and pain, and ended up in hospital. With all the pain meds the hospital was giving me, I was still in a lot of pain. The surgical team did several scans and tests but couldn't find the cause of the pain. I was becoming increasingly ill, the hospital at [anonymised] decided to transfer me to [anonymised].

My condition was rapidly deteriorating, and the Drs couldn't find the cause, but they knew my kidneys were failing. Mind you, before my septoplasty op I had perfectly healthy kidneys. And I thought I was going to die and finally the Drs decided to do a CT angiogram of my arteries and it was then that they discovered that my arteries were blocked with blood clots, and it was preventing the blood supply to my kidneys. It took 4 days approximately to find the cause for my kidney failure, but after the Drs realised the issue, they did everything within their power and knowledge to treat me, and so the journey to recovery began.

Having said all of the above and being very grateful to the Drs/nurses and the entire staff who looked after me so well, it is my faith to believe that God helped me recover, my family and friends prayed very hard for my recovery, and I like to acknowledge that as well.

So that's my story in a nutshell. 
Learning points

- Isolated thromboembolic renal infarction can occur without overt extrarenal infarcts, presumably due to the relatively high blood flow rate through the kidneys. Renal infarction should be suspected in patients with acute abdominal pain, oliguria or acute kidney injury (AKI), and a significantly elevated lactate dehydrogenase.

- An early hypertensive response and neutrophilic leucocytosis, combined with a slightly delayed but robust elevation in C reactive protein are additional clues of renal infarction.

- CT angiography (or magnetic resonance angiography) is necessary to detect renal thromboembolism in patients with suspected renal infarction. lodinated contrast may be given despite AKI as intervention to establish reperfusion may rescue patients with total or subtotal bilateral renal artery occlusion from permanent dialysis. The risks and benefits of intervention should be discussed as soon as the diagnosis is established.

- Some patients with renal artery occlusion may benefit from catheter-directed revascularisation up to 88 hours from the onset of symptoms despite AKI needing dialysis.

- It is reasonable to evaluate patients for a patent foramen ovale if paradoxical emboli are suspected before the renal infarct is considered idiopathic.

the timing of the procedures relative to the onset of symptoms was not reported.

Contributors JLL was involved in the acute care of the patient. JLL conceptualised the case report, collected the initial data and drafted the manuscript. KKL was the interventional radiologist who treated the patient, and provided the original figures and images for publication. AKHL revised the original manuscript, collected further follow-up data, formatted, labelled and compiled the images as publication figures, contributed to fact checking, discussion and learning points. All authors have read and approved the final version.

Funding The authors have not declared a specific grant for this research from any funding agency in the public, commercial or not-for-profit sectors.

Competing interests None declared.

Patient consent for publication Consent obtained directly from patient(s).

Provenance and peer review Not commissioned; externally peer reviewed.
Open access This is an open access article distributed in accordance with the Creative Commons Attribution Non Commercial (CC BY-NC 4.0) license, which permits others to distribute, remix, adapt, build upon this work non-commercially, and license their derivative works on different terms, provided the original work is properly cited and the use is non-commercial. See: http://creativecommons.org/ licenses/by-nc/4.0/.

Case reports provide a valuable learning resource for the scientific community and can indicate areas of interest for future research. They should not be used in isolation to guide treatment choices or public health policy.

\section{ORCID iDs}

Kenneth K Lau http://orcid.org/0000-0002-7424-9947

Andy K H Lim http://orcid.org/0000-0001-7816-4724

\section{REFERENCES}

1 Bourgault M, Grimbert P, Verret C, et al. Acute renal infarction: a case series. Clin J Am Soc Nephrol 2013:8:392-8.

2 Oh YK, Yang CW, Kim Y-L, et al. Clinical characteristics and outcomes of renal infarction. Am J Kidney Dis 2016:67:243-50.

3 Hazanov N, Somin M, Attali M, et al. Acute renal embolism. Forty-four cases of renal infarction in patients with atrial fibrillation. Medicine 2004;83:292-9.

4 Carey HB, Boltax R, Dickey KW, et al. Bilateral renal infarction secondary to paradoxical embolism. Am J Kidney Dis 1999;34:752-5.

5 Jeong $\mathrm{H}$, Woo Lee $\mathrm{H}$, Young Joung J, et al. Renal infarction caused by paradoxical embolism through a patent foramen ovale. Kidney Res Clin Pract 2012;31:196-9.

6 Herbaut AG, Mahieux P, Contu E, et al. Renal infarction caused by paradoxical embolism. Am J Emerg Med 1985;3:206-7.

7 Goueffic Y, Carbajal R, Burban M, et al. Successful endovascular treatment of bilateral renal artery paradoxical embolus by a modified standard technique. Nephrol Dial Transplant 2006:21:2315-7.

8 Shah R, Nayyar M, Jovin IS, et al. Device closure versus medical therapy alone for patent foramen ovale in patients with cryptogenic stroke: a systematic review and meta-analysis. Ann Intern Med 2018;168:335-42.

9 Windecker S, Wahl A, Nedeltchev K, et al. Comparison of medical treatment with percutaneous closure of patent foramen ovale in patients with cryptogenic stroke. $J$ Am Coll Cardiol 2004;44:750-8.

10 Ouriel K, Andrus CH, Ricotta JJ, et al. Acute renal artery occlusion: when is revascularization justified? J Vasc Surg 1987;5:348-55.

11 Critoph C, Radvan J, Shepherd D. Acute renal artery embolism treated with a cardiac thrombectomy catheter. BMJ Case Rep 2009;2009:bcr2007115618.

12 Decoste R, Himmelman JG, Grantmyre J. Acute renal infarct without apparent cause: a case report and review of the literature. Can Urol Assoc J 2015;9:237-9.

13 Konings R, Lely RJ, Nurmohamed SA, et al. Successful reversal of acute kidney failure by ultrasound-accelerated thrombolysis of an occluded renal artery. Case Rep Med 2014;2014:1-4.

14 Arabi M, Vellody R, Cho K. Acute renal artery occlusion with prolonged renal ischemia: a case of successful treatment with stent placement and Catheter-directed thrombolysis. J Clin Imaging Sci 2011;1:11.

Copyright 2022 BMJ Publishing Group. All rights reserved. For permission to reuse any of this content visit

https://www.bmj.com/company/products-services/rights-and-licensing/permissions/

BMJ Case Report Fellows may re-use this article for personal use and teaching without any further permission.

Become a Fellow of BMJ Case Reports today and you can:

- Submit as many cases as you like

- Enjoy fast sympathetic peer review and rapid publication of accepted articles

Access all the published articles

Re-use any of the published material for personal use and teaching without further permission

Customer Service

If you have any further queries about your subscription, please contact our customer services team on +44 (0) 2071111105 or via email at support@bmj.com.

Visit casereports.bmj.com for more articles like this and to become a Fellow 